\title{
O desafio historicista à economia política: uma análise do debate metodológico na Inglaterra na década de 1870 *
}

\author{
Laura Valladão de Mattos **
}

\begin{abstract}
Resumo
Esse artigo analisa um debate, ocorrido na década de 1870, que se seguiu a fortes críticas lançadas por dois economistas historicistas, Thomas Cliffe Leslie e John Kells Ingram, à natureza dedutiva, abstrata e universalista da Economia Política. O objetivo desses economistas era substituir essa ciência por uma Economia de caráter indutivo e histórico. Walter Bagehot e William Stanley Jevons - defensores, respectivamente, da ortodoxia vigente e do marginalismo emergente - reagiram diretamente a esses críticos. A resposta de Bagehot foi reafirmar o método dedutivo da Economia Política, porém restringir a validade dessa ciência às sociedades comerciais avançadas como a Inglaterra. A reação de Jevons foi enfatizar a natureza dedutiva e universal da teoria econômica, mas defender a importância da existência de ramos de históricos e aplicados de investigação. Argumenta-se que, o desafio historicista colocou as questões metodológicas na 'ordem do dia' e fez com que esses economistas atribuíssem um 'lugar' para a história - mesmo que não aquele almejado por Leslie e Ingram. Analisar esse debate metodológico permite uma compreensão melhor das alternativas que se apresentavam para a Economia ao final do século XIX e pode, quem sabe, jogar luz sobre os rumos que a nossa ciência tomou nas primeiras décadas do século XX.
\end{abstract}

Palavras chave: Historicismo; Cliffe Leslie (1825-1882); John Ingram (1963-); Walter Bagehot (1826-1877); Stanley Jevons (1835-1882).

\begin{abstract}
The historicist challenge to political economy: an analysis of the methodological debate in England in the 1870's

This paper analyzes a debate that occurred in the 1870's as a consequence of the challenge that two historicist economists - Thomas Cliffe Leslie and John Ingram - posed to the deductive, abstract and universal nature of Political Economy. The aim of these economists was to replace the deductive science of Political Economy with an inductive and historical science. Walter Bagehot and William Stanley Jevons - representing respectively the prevailing orthodoxy and the emergent marginalism - reacted directly to these critics. Bagehot's answer was to reaffirm the deductive method of Political Economy, and to restrict its validity to advanced commercial societies such as England. Jevons's reaction was to emphasize the deductive and universalist character of economic science, but also defend the necessity to develop historical and applied branches of economic investigation. It is argued that the historicist challenge placed methodological questions in the 'order of the day' of economic discussions, and led Bagehot and Jevons to ascribe a 'place' to history - even if not the one aspired by Leslie and Ingram. The analysis of this debate helps us to better understand the alternatives that existed for Economics in the late nineteenth-century, and might shed light on the direction that our science followed in the first decades of the twentieth century.
\end{abstract}

Keywords: Historicism; Cliffe Leslie; John Ingram; Walter Bagehot; Stanley Jevons.

JEL B1, B15, B5.

\section{Introdução}

Quando pensamos no que ocorreu em termos de pensamento econômico nas últimas décadas do século XIX na Inglaterra, em geral, o que vem à mente são as críticas lançadas pelo

\footnotetext{
* Artigo recebido em 23 de agosto de 2017 e aprovado em 25 de setembro de 2017.

${ }^{*}$ Professora do Departamento de Economia da Faculdade de Economia e Administração da Universidade de São Paulo (FEA-USP), São Paulo, SP, Brasil. E-mail: lauramattos@usp.br.
} 
marginalista William Stanley Jevons à Economia Política Clássica e, depois, a grande obra econômica de Alfred Marshall, que 'enterrou' definitivamente a ortodoxia Clássica e deu início a uma nova forma de fazer Economia.

Essa narrativa está correta, mas perde de vista o fato de que aproximadamente vinte anos separam as publicações de A Teoria da Economia Política de Jevons em 1871 e dos Princípios de Economia de Marshall em 1890 - período de muitas controvérsias entre os economistas, e no qual o futuro da nossa ciência parecia indefinido. ${ }^{1}$

Na década de 1870, a Economia Política Clássica foi desafiada não somente pelo projeto de Jevons de construção de uma teoria econômica dedutiva e matemática baseada na utilidade e no interesse individual, mas também por economistas historicistas, cujas críticas e propostas contestavam tanto a ortodoxia vigente, como a emergente economia marginalista.

Houve, assim, nesse período um embate não entre duas, mas entre três visões bastante diferentes de Economia. De um lado, a ortodoxia Clássica, de outro, as duas escolas rivais que buscavam substituí-la (Koot, 1980, p. 179). E, pelo menos por um tempo, os historicistas pareciam levar a melhor. Como sugere Maloney: “[...] entre os seus dois herdeiros em potencial, marginalismo e historicismo, eram os historicistas que estavam em sintonia com o clima intelectual geral da época" (Maloney, 2008, p. 1). ${ }^{2}$

Esse artigo se propõe a analisar um debate que se seguiu ao desafio lançado por dois economistas historicistas, Thomas Cliffe Leslie e John Kells Ingram, em meados da década de 1870, às vertentes dedutivas da economia. Eles criticaram a pretensão universalista da ciência da época, o seu método de investigação, e as políticas que os economistas defendiam usando por base o conhecimento fornecido pela ciência abstrata da Economia, e defenderam substituíla por uma ciência indutiva e histórica da Economia. Evidentemente muitos de seus contemporâneos simplesmente ignoraram essas ideias e continuaram a defender, sem alterações, os métodos até então utilizados pela Economia Política. No entanto, dois importantes economistas da época, Walter Bagehot e William Stanley Jevons - defensores, respectivamente, da ortodoxia Clássica e do marginalismo - reagiram diretamente a esses críticos. A resposta de Bagehot foi a de, por um lado, reafirmar a Economia Política Clássica e seu método de investigação, mas por outro, restringir a sua validade às sociedades comerciais avançadas como a Inglaterra. Jevons, por sua vez, propõe subdividir o campo da Economia e,

(1) Como aponta Coats (1954), essa intensa divergência se revelou de forma explícita em um jantar em comemoração ao centenário da publicação da Riqueza das Nações (em 1876) realizado no Clube de Economia Política. A falta de consenso no jantar era tanta que, segundo Jevons, "[a]lguns jornais sugeriram [...] que os economistas políticos deveriam estar celebrando as exéquias e não o jubileu de sua ciência" (Jevons, 1876, p. 619).

(2) Phyllis Dean também ressalta a força do historicismo na época: "Na década de 1870, a comunidade intelectual dos economistas [...] não era nem um pouco receptiva à noção de que o primeiro passo em direção a um consenso científico genuíno seria a construção de uma teoria geral e matemática do valor. Pelo contrário, ela estava mais abalada pelos ataques [...] que vinham da direção oposta, isto é, dos historicistas, que acusavam os economistas de serem muito abstratos e irrealistas nas suas teorias e procedimentos analíticos (Dean, 1989, p. 130). A autora ressalta o enorme prestigio desfrutado pela História na época, o que reforçava as demandas de que a Economia deveria adotar o mesmo método que estava tendo sucesso nessa disciplina (Dean, 1989, p. 132). 
ao mesmo tempo em que reafirma a natureza dedutiva e universal da teoria econômica propriamente dita, defende a importância da existência de ramos históricos e aplicados de investigação econômica. Assim, argumenta-se no artigo que, apesar dos dois rechaçarem a maior parte das ideias historicistas, o desafio por eles lançado fez com que atribuíssem um 'lugar' para a história - apesar de não ser aquele almejado por Leslie e Ingram.

Embora muito relevante na época, e interessante ainda hoje, esse episódio foi relativamente pouco tratado pela literatura secundária - principalmente se comparado à enorme atenção dada à reação marginalista à Economia Política Clássica e ao methodenstreit alemão. ${ }^{3}$ Acredita-se que analisar esse debate metodológico nos permite compreender melhor as alternativas que se apresentavam para a Economia ao final do século XIX e, quem sabe, jogar luz sobre os rumos que a nossa ciência tomou nas primeiras décadas do século XX.

O artigo está dividido em quatro seções além dessa introdução. Na seção 1, as críticas dos historicistas Cliffe Leslie e John Ingram à ortodoxia vigente serão expostas. Na seção 2, as respostas de Walter Bagehot e de Stanley Jevons a esse desafio serão analisadas. E, por fim, algumas considerações sobre as consequências dessa controvérsia para os rumos da Economia serão apresentadas.

\section{As críticas historicistas à economia política}

\subsection{Contexto histórico}

Antes de abordarmos as críticas dos historicistas, é importante expor, ainda que rapidamente, o contexto no qual elas surgiram e o que estava em jogo nessa 'batalha dos métodos'.

A denominação de 'escola histórica inglesa' não é totalmente adequada, uma vez que os seus dois principais protagonistas no período em análise, Thomas Edward Cliffe Leslie e John Kells Ingram, eram irlandeses. ${ }^{4}$ E não foi mero acaso que o historicismo de língua inglesa tenha se originado nesse país.

A Irlanda tinha uma condição social e econômica muito diferente daquela existente na Inglaterra e, no entanto, era administrada por esse país de acordo com princípios e preceitos econômicos derivados tendo em vista a realidade inglesa e não as especificidades da sociedade irlandesa (Hodgson, 2001, p. 65-67).

Em nome das 'leis universais da Economia Política', foram implementadas políticas que levaram a resultados desastrosos na Irlanda e culminaram na grande fome irlandesa de

(3) Há, no entanto, uma reduzida literatura secundária sobre o tema (apesar de muitas vezes tratar apenas de alguns dos aspectos a serem aqui abordados) que será extensamente utilizada ao longo do trabalho.

(4) Por conta desse fator geográfico Hodgson (2001, p. 66) repudia totalmente a denominação 'Escola histórica inglesa': "[...]não nenhuma boa desculpa para o persistente uso de termos inapropriados tais como 'Escola histórica inglesa" [...] O fato de boa parte do debate sobre a economia política ter ocorrido em Londres na Inglaterra não é uma justificativa suficiente tendo em vista a origem irlandesa de muitos de seus importantes protagonistas” (Hodgson, 2001, p. 66). No entanto, feita essa qualificação, seguiremos a literatura e utilizaremos a nomenclatura usual de escola histórica inglesa. 
meados do século XIX - calamidade social que matou aproximadamente um milhão de pessoas e fez com que mais de dois milhões de irlandeses deixassem o país (Gray, 1995, p. 94 e Kinzer, 2001, p. 89). E o apelo aos mesmos 'princípios econômicos' era utilizado, igualmente, para rechaçar reformas econômicas e sociais que, segundo a visão de muitos irlandeses, poderiam equacionar os enormes problemas do país. Assim, como explicita Koot, "[a escola histórica inglesa] teve sua raiz na busca de soluções os problemas sociais e econômicos da Irlanda problemas para os quais a economia ortodoxa britânica não parecia oferecer uma solução" (Koot, 1975, p. 336).

No centro do desafio historicista estava, portanto, um questionamento da pretensa 'universalidade' dos princípios da Economia Política Clássica. Rejeitava-se a pertinência de transpor os princípios desenvolvidos tendo em vista a Inglaterra para outras sociedades, como a irlandesa, com cultura, hábitos, história e características econômicas e sociais diferentes (Hodgson, 2001, p. 67).

Quando analisamos o seu contexto de origem, fica claro que, apesar de o embate dos historicistas com a ortodoxia econômica ter se dado basicamente em termos metodológicos, havia muito mais em jogo. Colocava-se em dúvida, principalmente, se a ciência econômica dedutiva e abstrata que era desenvolvida pela ortodoxia vigente seria um bom fundamento para a formulação de preceitos e políticas. Com apontam Collini et al.:

[...] era, acima de tudo, o seu papel de comando nas discussões de assuntos públicos que fazia da Economia Política algo pelo qual tão claramente valia a pena lutar, e era o entendimento deste papel que os economistas históricos tentavam, acima de tudo, alterar (Collini et al., 1983, p. 274-275).

E esses questionamentos mais gerais sobre a universalidade dos princípios e dos preceitos da economia política clássica, fundamentaram-se em uma radical crítica à metodologia adotada pelos economistas da época.

\subsection{Crítica dos historicistas ao método dedutivo e abstrato da ortodoxia clássica}

O radical desafio metodológico dos historicistas teve como alvo central a natureza dedutiva e abstrata dessa ciência. Eles questionaram a ambição de se construir uma ciência separada (e autônoma) da Economia Política e rejeitaram a possibilidade de utilizar o conhecimento abstrato e a-histórico fornecido por essa ciência como fundamento para a formulação de políticas econômicas.

A economia ortodoxa - que ainda tinha como principal referência J.S. Mill - fundava a sua ciência em um pequeno conjunto de motivações humanas, conhecidas por introspecção e consideradas universais ${ }^{5}$. Partia-se da ideia de que na esfera dos assuntos econômicos os homens eram prioritariamente motivados pela busca da riqueza, e por duas motivações que

(5) Esse artigo não tem como objetivo discutir o método defendido por J.S. Mill e aceito pela maior parte dos economistas políticos clássicos. A estratégia é enuncia-lo de forma rápida para que as críticas dos historicistas se tornem inteligíveis. Para a visão de Mill sobre metodologia da Economia Política ver Mill ([1844], 1967) e Mattos (2004). 
perpetuamente a ela se contrapunham: o desejo de consumir coisas dispendiosas e a aversão ao trabalho (Mill, [1844], 1967, p. 321). Esses economistas sabiam que outras motivações também afetavam a ação econômica dos homens, no entanto, consideravam que a preponderância desse conjunto de motivações era grande o suficiente de forma a justificar estudo dos resultados que seguiriam caso essas fossem as únicas motivações em ação. Com esse argumento justificavam a ciência separada e dedutiva da Economia Política, erigida sobre esse pequeno conjunto de motivações humanas relacionadas à riqueza (Mill, [1844], 1967, p. 323).

Uma vez que os resultados da ciência eram obtidos considerando apenas algumas (as mais importantes) das motivações que efetivamente determinavam o comportamento econômico, ela seria uma 'ciência abstrata' e afirmaria apenas tendências. Não seria de se esperar uma concordância exata entre os resultados da ciência e a realidade já que a ciência propositadamente omitia uma série de fatores que poderia ser relevante no caso em questão.

Assim, a Economia Política ortodoxa era concebida como uma ciência abstrata, dedutiva e autônoma. Contra essa concepção, os historicistas propunham uma ciência indutiva, histórica e muito proximamente articulada com a Sociologia. Como descreve Bladen: "J. K. Ingram e Cliffe Leslie [...] queriam reconstruir a Economia sobre uma base indutiva e observacional" (Bladen, 1941, p. 2) .

No centro do desafio historicista estava uma crítica à abstração 'homem econômico', a partir da qual eram deduzidas as leis de funcionamento e os resultados da ciência econômica. Inclusive quem cunhou o termo - que tinha na sua formulação original um sentido pejorativo - foi o John Ingram, quando acusou a Economia Política de "[ ...] lidar não com homens reais, mas com homens imaginários - 'homens econômicos'.... concebidos como meros animais acumuladores de dinheiro" (Ingram apud Persky, 1995, p. 222).

Cliffe Leslie, que deu o pontapé inicial ao methodenstreit inglês da década de 1870 (Koot, 1975, p. 313), também centrou fogo no pressuposto comportamental assumido pela ortodoxia da época, que considerava ser "[...] um estereótipo psicológico irreal, totalmente incapaz de sustentar a pirâmide de deduções lógicas jogadas sobre ele [...]" (Leslie apud Maloney, 2008, p. 2) ${ }^{7}$.

Um primeiro problema apontado era o fato de o desejo de riqueza - motivação básica da economia política - ser na verdade uma abstração que agregava várias motivações significativamente diferentes como se fossem uma única motivação homogênea (Leslie, 1876, p. 186). A esse respeito o autor afirma:

(6) Na interpretação de Tribe, os historicistas apresentavam um “[...] projeto de construção de uma ciência histórica indutiva, na qual a diversidade das circunstâncias econômicas fosse adequadamente reconhecida. Assim, o que une todas essas preocupações com o projeto de uma economia histórica [...] é uma lealdade a uma abordagem indutivista e empiricista à teoria econômica, e uma hostilidade à economia dedutiva [...]" (Tribe: 2002, p. 1).

(7) Sobre as hipóteses comportamentais das quais parte a Economia Política, Leslie afirma: "O ser humano ou 'indivíduo' a partir de cujas tendências assumidas as conclusões do sistema dedutivo são traçadas e suas predições feitas, é uma ficção e não uma realidade - a personificação de duas abstrações, o desejo por riqueza e a aversão ao trabalho - sentimentos que diferem [...] em diferentes países, épocas e pessoas [...]" (Leslie, [1879], 1888, p. 207). 
Nenhum tal princípio como 'o desejo de riqueza', no sentido de uma única motivação universal, cujas consequências são uniformes e previsíveis, realmente existe (Leslie, [1879], 1888, p. 198).

Ele acreditava que 'riqueza' abarcava uma variedade muito grande de coisas e que as formas específicas de riqueza que seriam buscadas, os desejos a elas relacionados e as consequências que deles derivariam em termos da produção e da distribuição do produto, variavam de modo significativo ao longo da história (Leslie, [1879], 1888, p. 199): ${ }^{8}$

No que concerne à natureza da riqueza [...] diferenças essenciais em seu tipo e constituintes, que afetam profundamente as condições econômicas da humanidade, manifestam-se em diferentes estágios de progresso [...] (Leslie, 1876, p. 189).

Resumindo e subscrevendo as ideias de Leslie, Ingram afirma:

O ponto sobre o qual o Sr. Leslie insiste [...] não é meramente [...] que a frase desejo por riqueza representa uma generalização grosseira e rudimentar na história natural do homem; mas que os vários impulsos incluídos sob esse nome assumem formas diferentes e variam na sua força relativa e, portanto, produzem consequências econômicas diversas em diferentes estados de sociedade; e que a abstração incorporada na frase é por demais vaga e irreal para ser utilizada em uma investigação econômica de caráter realmente cientifico (Ingram, 1878, p. 15-16).

Ao ignorar esses aspectos, e tratar 'desejo por riqueza' como algo homogêneo e imutável, a Economia Política dedutiva deixava de fazer as perguntas que os historicistas consideravam as mais relevantes. Como, por exemplo: Qual seria o tipo de riqueza buscada em determinada época e local? Como ela era adquirida e utilizada? Como esses fatores variavam em diferentes estados de sociedade, e com diferentes instituições e circunstâncias históricas?

O uso da abstração 'busca por riqueza' levava a Economia dedutiva a desconsiderar, ainda, o efeito das instituições e da sociedade sobre o tipo de riqueza desejado:

Os próprios desejos e objetivos [wants and aims] sumarizados no 'desejo de riqueza' surgem não de propensões inatas, originais e universais do homem individual, mas da comunidade e sua de história (Leslie, [1879], 1888, p. 212).

Para os historicistas, o presente só poderia ser compreendido à luz do passado e, por isso, havia uma enorme ênfase no estudo da evolução dos fenômenos econômicos (Keynes, [1890] 1985, p. 80-81) $)^{9}$ Eles criticavam a Economia Política da época por perder totalmente

(8) As motivações envolvidas possuem caráter diverso em diferentes épocas: “[ $[$ ] anto os desejos que têm por objeto os diferentes tipos de riquezas, como os desejos que competem com eles, são, em todas as nações, resultado de seu curso histórico e seu estado de civilização" (Leslie, 1876, p. 177-178).

(9) Leslie frisa esse ponto: "Todo estado que sucede [sucessive state][...] tem uma economia indissoluvelmente conectada com o desenvolvimento intelectual, moral e civil; e a condição econômica da sociedade inglesa hoje é o resultado de todo o movimento que desenvolveu a constituição política, a estrutura da família, as formas de religião, as profissões aprendidas, as artes, a ciência, e o estado da agricultura, manufatura e comércio. O método filosófico da economia política tem que ser tal que exponha essa evolução" (Leslie, 1876, p. 190). 
de vista essa dimensão histórica do comportamento econômico. Ela ignoraria as diferenças existentes entre diversos países e épocas no que tange ao que efetivamente era desejado como riqueza, a como a riqueza era produzida e distribuída e à evolução dessas coisas ao longo do tempo, deixando a sua marca no presente (Leslie, 1876, p.189). E isso estaria, segundo Ingram, na base da tendência observada entre os economistas ingleses de atribuírem um status universal à Economia Política e às conclusões obtidas por meio dela:

Segue [...] de seu método a priori e a-histórico que eles [os economistas políticos] chegam a resultados que alegam ser aplicáveis a todos os estados de sociedade. Ao negligenciarem o estudo do desenvolvimento histórico, eles tendem em medida excessiva a conceber a estrutura da sociedade como um tipo imutável [...] (Ingram, 1878, p. 24) ${ }^{10}$.

Dada a visão que tinham de sociedade, esses historicistas também questionavam a própria possiblidade de existência de uma ciência separada e dedutiva da Economia Política. Tanto Leslie como Ingram frisavam a enorme interdependência existente entre os fenômenos econômicos e os demais fenômenos sociais - o que traria problemas adicionais para o procedimento adotado pela ortodoxia econômica da época de fundar a ciência econômica apenas nas motivações relacionadas ao desejo por riqueza.

Leslie, um pouco menos radical que seu compatriota, admitia a legitimidade de selecionar os fenômenos econômicos como objeto específico de estudo, mas enfatizava a importância de fatores morais, religiosos, afetividades familiares, militares, etc. na ação econômica do homem:

O que chamamos de forças econômicas não só estão conectadas às forças que são também morais e intelectuais, como são idênticas a elas. Os desejos que governam a produção, a acumulação, a distribuição e o consumo da riqueza são paixões, apetites, afeições, sentimentos morais e religiosos, sentimentos pela família, gostos estéticos e desejos intelectuais (Leslie, 1876, p. 177-178).

É certo que a ortodoxia clássica também admitia que fatores 'extra riqueza' afetavam a ação econômica dos homens, todavia alegava que a sua consideração só seria relevante na hora de aplicar os princípios da ciência à prática. Nesse momento, seria necessário levar em conta os fatores que, no caso específico em questão, se somariam aos efeitos da busca de riqueza na determinação dos resultados concretos. No entanto, a consideração destes fatores seria relevante para somente para a 'arte', e não para a 'ciência' da Economia Política - que, como vimos, seria desenvolvida como um ramo abstrato e autônomo do saber. Os historicistas obviamente não compartilhavam essa visão. Ingram, por exemplo, afirma a esse respeito: "Para

(10) Sobre universalismo da economia clássica inglesa, o autor afirma: "A verdade é que na maior parte das asserções dos teoremas econômicos pela Escola Inglesa, a prática é pressupor tacitamente que o estado de desenvolvimento social e as condições históricas e sociais gerais são similares aos da Inglaterra moderna [...]" (Ingram, 1878, p. 25). Ressalta ainda: "O caráter absoluto da economia política atual é evidenciado não só por sua negligência da influência do estado geral da sociedade, mas também pela forma ilimitada e incondicional que dá à maior parte das suas conclusões” (Ingram, 1878, p. 15). 
os propósitos tanto da teoria como da prática os vários ramos da investigação social estão inseparavelmente entrelaçados [...]" (Ingram, 1878, p. 12).

Para eles, múltiplas motivações seriam importantes para explicar a ação econômica e seria incorreto e radicalmente 'não-científico' "[...] isolar uma única força, mesmo que seja real [...] e chamar as deduções a partir dela de leis da riqueza" [...] (Leslie, [1879], 1888, p.212). O tratamento da questão deveria ser realista (e não abstrata) e, portanto, seria necessário lidar com toda a natureza do homem. ${ }^{11}$

De toda forma, feitas essas qualificações, Leslie considerava que seria possível estudar os fenômenos econômicos como um ramo da ciência da sociedade. Ele afirma:

[...] a economia política é, portanto, um departamento da ciência da sociedade que seleciona uma classe especial do fenômeno social para investigação especial, mas para esse propósito deve investigar todas as forças e leis que a governam (Leslie, [1879], 1888, p. 212, grifo adicionado) $)^{12}$.

John Ingram, por sua vez, influenciado por Auguste Comte, defendeu que a Economia deveria ser dissolvida na Sociologia. Em palestra proferida enquanto era o presidente da Seção $F$ (Ciência Econômica e Estatística) da British Association for Advancement of Science, Ingram declara:

[...] me parece que seja como um ramo frutífero de especulação, ou como importante fonte de orientação prática, ela [a Economia Política] deixará de comandar, ou fracassará em reconquistar, atenção [...] a não ser que, de fato, seja subsumida à Sociologia e absorvida por ela (Ingram, 1878, p. 14) ${ }^{13}$.

Assim, a alegação desses historicistas era a de que o estudo dos fenômenos econômicos não poderia ser empreendido, nem em um primeiro momento, de forma autônoma ou separada levando em conta somente um pequeno conjunto de motivações humanas, e que a investigação econômica deveria ser feita, quando muito, como um ramo da Sociologia.

Para eles, seria impossível ter um conhecimento a priori (ou intuitivo) a respeito de todas as outras motivações (além daquelas relacionadas à riqueza) que influenciam a conduta

(11) Como descreve Neville Keynes ao descrever as ideias da vertente historicista: "[...] o economista deveria somente de forma muito parcimoniosa, se é que deveria, [if at all], empreender uma abstração das realidades complexas da vida econômica real, e consequentemente, deveria[...] lidar não com um 'homem econômico' abstrato [...] mas com os homens tais como eles realmente são, movidos por diversas motivações e influenciados pelas condições reais da época e sociedade em que vivem. [...]" (Keynes, [1890], 1965, p. 80).

(12) Como as propostas ficaram num nível programático, não é fácil vislumbrar o tipo de Economia que resultaria dessa concepção historicista. Collini et al., no entanto, fazem esse exercício no que concerne às ideias de Leslie e concluem: "[...] Especificada de forma abstrata, parece que resulta em uma sociologia histórica vagamente concebida, na qual os arranjos econômicos são relacionados a mudanças nos gostos, nos valores religiosos e morais, nos arranjos políticos e legais e assim por diante" (Collini et al., 1983, p. 264).

(13) De todo modo, para os dois historicistas, “[a] abstração do 'homem econômico' não era uma base razoável para analisar o fenômeno econômico e o desejo de riqueza, tal como qualquer outro motivo específico não é suficiente para sustentar uma ciência separada da economia" (Zouboulakis, 2008, p. 97). 
humana e do peso relativo destas em cada momento do tempo ${ }^{14}$. Fazia-se necessária uma cuidadosa e extensiva pesquisa indutiva e histórica de forma a se conhecer os princípios importantes para a ação econômica na sociedade e na época específica sob investigação. Eles advogavam que, ao invés de 'partir' de princípios, como fazia a ortodoxia econômica da época, seria necessário 'chegar' a esses princípios por meio de observação empírica sistemática dos fenômenos econômicos e da sua histórica. E mesmo os princípios assim obtidos não seriam universais, e sim pertinentes apenas à situação histórica particular para a qual foram formulados.

Era esse estudo histórico e indutivo cuidadoso, e não o conhecimento abstrato fornecido pela doutrina econômica vigente, que deveria fornecer as bases para uma economia aplicada capaz de servir de orientar a intervenção social (Koot, 1975, p. 336). Em referência a Leslie, Koot afirma:

[...] ele acreditava que um paciente tratamento histórico, comparativo e estatístico dos assuntos econômicos [...] era o único caminho verdadeiro para criar uma economia política capaz de servir de guia para a formulação de políticas públicas (Koot, 1980, p. 183$)^{15}$.

Não que os historicistas fossem em princípio contra utilização do método dedutivo. Eles criticavam a Economia Política por esta utilizar como base para as suas deduções princípios que eram simplesmente 'assumidos', sem o necessário estudo empírico prévio. ${ }^{16}$ Nesse sentido, falando em nome da sua 'escola', Cliffe Leslie afirma:

Nós [historicistas] somos [...] pela eliminação do método dedutivo de Ricardo: quer dizer, da dedução a partir de hipóteses não verificadas [...]. Porém, não somos contra a dedução a partir de generalizações e princípios verificados, ainda que consideremos a tarefa urgente do presente como sendo a indução, e encaremos longas sequências dedutivas com suspeição (Leslie [1879], 1984, ênfase adicionada).

(14) Para Leslie os seguidores da economia dedutiva se encontravam diante de um dilema: Ou admitem que homem é motivado apenas por riqueza " [...] ou devem aceitar que possuem um conhecimento intuitivo de todas as motivações morais, políticas e outras que influenciam a conduta humana, e de todas as mudanças pelas quais elas passam em diferentes países e períodos" (Leslie, [1879], 1888, p. 202) - o que, obviamente, não seria razoável.

(15) Como resume Koot: "Para combater o falso universalismo da economia ortodoxa, Leslie promoveu a posição historicista de que políticas econômicas, instituições e teorias deveriam ser relativas a uma época e uma localidade especifica [...]" (Koot, 1980, p. 183). Na mesma linha, Maloney afirma que um dos pontos que unem os historicistas era justamente a "[...] determinação em enfatizar que nenhuma teoria ou política poderia ser apropriada para todas as épocas e lugares, e a convicção de que tanto a economia clássica como a neoclássica eram muito abstratas para fornecer ao Estado ou ao cidadão alguma ajuda prática [much practical help]" (Maloney, 2008).

(16) Em uma descrição que resume, no meu entender, bem a posição dos seus colegas historicistas em relação à dedução/indução, Herbert $S$. Foxwell afirma: “[eles] se interessam comparativamente pouco pelas deduções, pois eles acreditam que os fatos não foram ainda observados de forma cuidadosa, que as hipóteses só têm uma relação remota com os fatos, que os fatos em si estão em processo de evolução e mudança e que a natureza e a direção dessa evolução social são objetos de estudo muito mais importantes do que deduções elaboradas e complicadas [...] eles se opõem ao dogmatismo arrogante [...] que se apoia em generalizações grosseiras e sobre uma base limitada de observação [...]" (Foxwell, 1887, p. 89). 
Em suma, o ataque dos historicistas à Economia Política foi bem radical. Eles criticavam o seu método, o seu escopo, a suposta universalidade das suas conclusões e a própria possibilidade de uma ciência autônoma da Economia Política. ${ }^{17}$ A sua demanda era por estudos indutivos e históricos minuciosos, que considerassem as particularidades nacionais, e engendrassem resultados localmente válidos, que pudessem embasar a formulação de políticas. Eles entendiam que somente depois de um estudo realista e detalhado das características históricas, culturais, institucionais e políticas e econômicas de uma dada sociedade (como, por exemplo, a Irlanda) seria possível chegar às leis econômicas a ela relativas e formular políticas adequadas para sanar os seus problemas específicos.

\section{As respostas da economia clássica e marginalista ao desafio historicista: $O$ caso de Walter Bagehot e Stanley Jevons}

$\mathrm{O}$ ataque historicista suscitou várias réplicas por parte dos defensores de uma economia dedutiva ao longo das décadas de 1870 e 1880. Dentre elas, as respostas de Walter Bagehot e de William Stanley Jevons são especialmente interessantes, uma vez que eles se posicionaram de forma original em relação às várias questões metodológicas que os historicistas conseguiram colocar na 'ordem do dia'. Como será visto, eles tomaram posição em relação à questão da universalidade/contingência dos pressupostos da ciência economia, ao método adequado à ciência (dedução/indução), à divisão entre ciência e a prática, e com respeito à possibilidade de estudo autônomo da Economia Política. E, apesar de se oporem às propostas historicistas, com as suas respostas os dois acabaram por designar um lugar para a 'história' na reflexão econômica.

\subsection{A reação de Walter Bagehot}

Walter Bagehot elaborou as suas posições metodológicas como uma reação direta ao ataque historicista à Economia Política Clássica (Moore, 1996, p. 229, 245). Ele se considerava um defensor da ortodoxia econômica e via na Economia Política um instrumento muito importante para resolver os problemas da Inglaterra. Mostrou-se, portanto, preocupado com a rápida e intensa perda de prestígio que essa ciência estava sofrendo e com aumento da descrença do público no que concerne a sua relevância. A esse respeito ele afirma:

[...] a posição da nossa Economia Política não é de todo satisfatória. Ela se encontra morta na mente do público. Não só ela não excita mais o mesmo interesse de antes, como também não desperta mais a mesma confiança (Bagehot, [1879], 1915, p. 92-93).

O interessante é que seu engajamento contra os historicistas acabou por gerar uma posição original no que concerne ao status da Economia Política ortodoxa (Zouboulakis, 1999,

(17) Ingram resume as suas propostas para a Economia Política da seguinte forma: "1) Que o estudo dos fenômenos econômicos deve ser combinado de forma sistemática com aquele de outros aspectos da existência social. 2) Que a tendência excessiva à abstração e a simplificações irreais deve ser revertida; 3) Que o método dedutivo a priori deve ser substituído pelo histórico e; 4) Que as leis econômicas e os preceitos práticos fundadas naquelas leis devem ser concebidas e expressadas numa forma menos absoluta [...]" (Ingram, 1878, p. 26). 
O desafio historicista à economia política: uma análise do debate metodológico na Inglaterra na década de 1870

p. 79). No intuito de 'salvar' a economia política ortodoxa, ele aceita parte das críticas dos historicistas, especialmente no que concerne à pretensão de universalidade da economia política vigente, e apresenta uma versão que alguns consideram extremamente relativista dessa teoria $^{18}$.

Bagehot parte do reconhecimento de que a referida perda de prestígio era culpa dos próprios economistas ortodoxos. Essa ciência era apresentada "[...] não como uma teoria das principais causas que afetam a riqueza em certas sociedades, mas como uma teoria da principal causa ou, as vezes mesmo, de todas as causas que afetam riqueza em todas as sociedades" (Bagehot, [1879], 1915, p. 105) ${ }^{19}$. Ele ressalta que os bons economistas admitiam a existência de 'fricções' ou 'causas perturbadoras' que podiam contrabalançar os efeitos das causas consideradas pela ciência econômica. No entanto, mesmo estes, deixavam os seus leitores com a impressão de que essas 'fricções' seriam algo secundário e que aquelas causas apontadas pela ciência seriam as principais e mais relevantes (Bagehot, [1879], 1915, p. 105).

Nas sociedades comerciais avançadas (como a Inglaterra), Bagehot considerava que essas 'fricções' ou 'causas perturbadoras' eram, de fato, secundárias e quase negligenciáveis. Destarte, no que concerne a essas sociedades, não tinha qualquer crítica a fazer à adoção do método dedutivo baseado no 'homem econômico'. No entanto, ele considerava esse procedimento totalmente inadequado quando aplicado a sociedades tradicionais ou 'nãoeconômicas' pois, nelas “[...] essas outras causas - que em alguns casos são umas e em outros, outras - são as mais ativas [...]" (Bagehot, [1879], 1915, p. 105), não fazendo sentido trata-las como 'residuais'.

Desta forma, apesar de se juntar à tradição ortodoxa na defesa da necessidade de uma análise econômica abstrata, esse economista acabou por se distinguir por sustentar explicitamente a relatividade histórica dos postulados da Economia Política - cuja validade estaria restrita apenas a sociedades comerciais avançadas como a Inglaterra. ${ }^{20}$ Ao contrário da maior parte dos economistas ortodoxos, ele estava pronto a admitir que muitas sociedades eram guiadas predominantemente pelo costume e pelos hábitos, ou seja, eram o que ele denominou de sociedades 'não-econômicas' (Collini et al., 1983, p. 256). No que concerne a elas, os pressupostos assumidos pela Economia Política não seriam observados e as conclusões derivadas a partir destes não teriam validade. E ele é bem explícito a esse respeito:

(18) Moore afirma a esse respeito: “[...] A forma extrema de relativismo de Bagehot foi articulada como uma resposta ao crescimento do movimento historicista, e ao desafio que eles representavam para as doutrinas ortodoxas" (Moore, 1996, p. 245).

(19) Ele aponta dois outros defeitos da Economia, que derivavam dessa pretensão à universalidade, e que colaboravam para o seu descrédito frente ao público: o caráter árido da ciência por conta da falta de ilustração histórica, e a correlata tendência a ficar no nível abstrato (sem se ocupar com a verificação) - uma vez que o estudo de sociedades específicas revelaria instâncias nas quais os princípios da ciência se aplicariam, mas também outras nas quais fracassam (Bagehot, [1879], 1915, p. 106).

(20) Segundo Moore, "Bagehot estava convencido de que as leis da economia política ortodoxa poderiam resolver os problemas sociais e econômicos da Inglaterra, e endossou, portanto, o método abstrato e dedutivo a ela associado. No entanto, ao mesmo tempo, as suas próprias faculdades lidavam com o concreto, e ele desconfiava de generalizações vazias e não-operacionais [...] Ele conseguiu reconciliar essas crenças ao tornar a aplicabilidade das abstrações relativas a um período e lugar” (Moore, 1996, p. 245). 
[...] nenhum esforço intelectual pode ser mais absurdo do que tentar aplicar as conclusões da nossa Economia Política às vidas das nações em um estágio não-comercial de sua existência (Bagehot, [1879], 1915, p. 163).

Assim, embora tenha saído em defesa da Economia Política ortodoxa, Bagehot se colocava claramente ao lado dos historicistas contra as pretensões universalistas desses economistas. Sobre o status da economia ortodoxa ele afirma: “[...] a nossa economia política [inglesa] não é algo questionável de validade ilimitada, mas algo muito certo e útil de extensão limitada" (Bagehot, [1879], 1915, p. 109). Para ele, "[...] a sua autoridade deve ser defendida, mas suas fronteiras demarcadas" (Bagehot, [1879], 1915, p. 106) ${ }^{21}$.

De fato, ele restringiu o campo em que a Economia Política seria aplicável, no entanto, no âmbito desse campo, sustentou afirmações bastante fortes sobre a validade da ciência. E isso não passou despercebido aos seus contemporâneos. Giffen, por exemplo, afirma em 1880:

O que Bagehot fez foi [...] provar, contra as alegações da Escola Histórica, que existe uma época e sociedade - todo o mundo dos negócios da Inglaterra no presente momento, e uma grande parte de outras comunidades - na qual as hipóteses da Economia Política Inglesa são aproximadamente verdadeiras no concreto bem como no abstrato (Giffen, apud Hodgson, 2001, p. 73) ${ }^{22}$.

Além disso, como apontam Collini et al. (1983, p. 257), o relativismo de Bagehot era limitado, uma vez que ele acreditava que a racionalidade tenderia a vencer o costume e o hábito mesmo nessas sociedades 'não-econômicas', e que na medida em que isso ocorresse, a Economia Política se tornaria crescentemente aplicável. Essa postura fica clara na seguinte passagem:

A Inglaterra foi a primeira - ou uma das primeiras - nação a mostrar essas características com tal vigor e tão isoladamente de forma sugerir a análise separada delas, mas na medida em que o mundo segue, características similares estão sendo desenvolvidas em uma sociedade após a outra[...] Da mesma forma que os 'homens do mundo' são iguais em

(21) No entanto, a metodologia de Bagehot não era apenas defensiva. Como afirma Moore, "[Bagehot] era particularmente crítico das alternativas propostas pelos historicistas ao método dedutivo. ” (MOORE, 1996, p.242). Ele atacou o método indutivo defendido pelos historicistas, frisou que colecionar fatos não faria progredir a ciência, e que a abstração era fundamental para a Economia Política Ele diz que o método (baconiano) que os historicistas sugerem foi tentado nas ciências físicas sem qualquer sucesso. Para Bagehot, o método bem sucedido nas ciências "[...] não tem sido aquele de descartar as especulações abstratas e sim de trabalhar essas especulações [working out abstract speculations]. ” (BAGEHOT, [1879], 1915, p.102). E, depois de defender a importância do raciocínio abstrato contra as críticas dos historicistas, Bagehot aproveita para dar uma alfinetada na teoria marginalista, que se opunha à ortodoxia: “[...] qualquer um que acredite que o que é ensinado na Inglaterra é objetável por ser muito pouco concreto em seu método e por se parecer pouco com a vida e os negócios, deve tentar a nova doutrina, que ele irá considerar muito pior nesses pontos" (Bagehot, [1879], 1915, p. 104).

(22) Pelo fato de Bagehot acabar negando a validade universal da Economia Política, alguns autores o classificam como historicista. No entanto, essa visão não parece correta. Como coloca Moore (1996) ele era um economista clássico tentando defender a ortodoxia de um ataque que estava ganhando adeptos. Como aponta Neville Keynes, o Bagehot não limitou a economia política ortodoxa às sociedades modernas para fazer avançar o historicismo, e sim "[...] para concentrar a atenção no fenômeno econômico e para evitar distrações que resultariam de se desviar para os fenômenos superficialmente correspondentes, mas essencialmente diferentes de épocas anteriores" (Keynes apud Moore, 1996, p. 246). 
O desafio historicista à economia política: uma análise do debate metodológico na Inglaterra na década de 1870

todos os lugares, o grande comércio também é igual em todo lado. As peculiaridades locais, e as circunstâncias perturbadoras antigas caem em ambos os casos; e é desse comércio único e uniforme que cresce diariamente [...] que a economia política inglesa aspira ser a explicação (Bagehot, [1879], 1915, p. 108-109)23.

Os historicistas perceberam a natureza da defesa da Economia Política feita por Bagehot e rejeitaram a sua saída. Apesar de concordarem plenamente com a ideia de que seria inadequado aplicar os princípios e preceitos da Economia Política a países muito diferentes da Inglaterra, a resposta apresentada por Bagehot não lhes pareceu convincente. Por conta das questões metodológicas já discutidas, eles acreditavam a Economia Política, tal como era desenvolvida, não seria adequada nem mesmo para a Inglaterra da época. Como afirma Leslie:

Apologistas recentes do método a priori e abstrato de raciocínio econômico se sentem forçados a confinar a sua aplicação ao estágio avançado da sociedade comercial [...] Ela é agora restrita por Mr. Bagehot a 'um único tipo de sociedade' [...] No entanto, o tipo de sociedade econômica que temos na Inglaterra [...] é um que exibe por todos os lados a influência de costumes, tradições, leis, instituições políticas, sentimentos religiosos e morais: é uma sociedade na qual o Estado, a Família, e mesmo a Igreja são elementos poderosos [...] e na qual os objetivos dos indivíduos, [...] a estrutura do comércio e as profissões não podem ser explicadas sem levar em conta a sua história (Leslie apud Bladen, 1941, p. 19).

De toda forma, na avaliação de Zouboulakis (1999, p. 89), com a sua defesa original, Bagehot atingiu o seu objetivo e contribuiu para fortalecer o Programa de Pesquisa Ricardiano contra os ataques dos historicistas na década de 1870 .

\subsection{A resposta de Jevons ao desafio historicista}

O ataque de William Stanley Jevons contra a ortodoxia de Ricardo / J. S. Mill é bem conhecido pelos economistas. Ele se rebela contra 'a influência nociva' da autoridade exercida por essa Escola, e certamente reserva boa parte de sua munição para derrota-la. Posiciona-se contra a sua teoria do valor e clama por uma Economia não apenas abstrata e dedutiva, mas, sobretudo, matemática. No entanto, como argumentado anteriormente, a ortodoxia clássica não era a única frente na qual Jevons tinha que combater. O desafio historicista também tinha como alvo o seu projeto para a Economia - e esse era um adversário poderoso e que não podia ser ignorado. Como afirma Robertson:

Por um tempo parecia que a 'Escola Histórica' poderia se erguer de forma a empurrar a economia como ciência, pelo menos temporariamente, para um lado [...] Talvez a oposição mais severa ao que Jevons representava tenha vindo do [...] Professor J. K. Ingram (Robertson, 1951, p. 230).

(23) Como conclui Zouboulakis: “[...] já que, de acordo com Bagehot, as sociedades evoluem de forma similar, o futuro pertence [lies ahead for] à economia política inglesa" (1999, p. 86). 
Por conta disso, Jevons também não ficou indiferente às críticas proferidas pela Escola Histórica. Afinal, ao criticarem o método dedutivo e abstrato na Economia, os historicistas também miravam o incipiente projeto marginalista de substituição à ortodoxia clássica. E Jevons, em 1876, reconhece a importância e influência dessa vertente rival:

É impossível ignorar o fato de que uma escola de autores que adotam uma visão radical das reformas necessárias em nossa ciência tem gradualmente se tornado importante. Eles questionam até mesmo a validade do método dedutivo [...][e]defendem que a ciência tem que ser totalmente modificada em termos de método e de conteúdo, e que deve tomar a forma de uma ciência histórica [...] (Jevons, 1876, p. 620) ${ }^{24}$.

A importância atribuía aos estudos históricos e estatísticos por Jevons, o fato de ele próprio ser um economista plicado $^{25}$ e a circunstância de tanto Jevons e como os historicistas terem elegido a ortodoxia vigente como alvo preferencial fizeram com que se alinhassem em alguns pontos.

De fato, Jevons valorizou a investigação histórica em medida maior do que os autores da ortodoxia clássica e procurou abrir um espaço para ela na Economia. A esse respeito ele afirma:

[...] Eu estou longe de pensar que o tratamento histórico da nossa ciência é falso ou inútil. Pelo contrário, eu o considero indispensável. O estado presente da nossa sociedade não pode ser explicado somente pela teoria. Temos que levar em conta o longo passado, do qual estamos constantemente emergindo (Jevons, 1876, p. 622) ${ }^{26}$.

Entretanto, apesar de seu reconhecimento do valor da história, Jevons discordava radicalmente da intenção historicista de substituir a teoria abstrata existente por um estudo indutivo e histórico dos fenômenos econômicos, o que levaria, no seu entender, à destruição desse ramo do saber e à virtual subsunção dessa ciência na Sociologia. Ele resume da seguinte forma a sua posição a esse respeito:

(24) No Prefácio à $2^{\mathrm{a}}$ edição da Teoria da Economia Política, escrito em 1879, Jevons volta a essa questão nos seguintes termos: "Uma discussão digna de nota tem ocorrido recentemente [...] sobre o método lógico da ciência [da economia política], que envolve até a questão de se existe tal ciência [...] É evidente, portanto, que uma atitude de crítica muito ativa está se espalhando, que dificilmente falhará em minar ao final o prestígio das falsas velhas doutrinas. Mas o que será colocada no seu lugar? [...] O Sr. Cliffe [...] reconstruiria a ciência em um modo puramente indutivo. Ela terá ou a natureza de uma miscelânea de fatos desconexos, ou terá que ser um ramo da [...] Sociologia" (Jevons, [1879] 1888, p. xiv).

(25) A posição que Jevons assume nesse debate é interessante por ele ter se dedicado a estudos aplicados, e por ter genuíno interesse em investigações empíricas. Na verdade, ele já era conhecido por seus trabalhos aplicados - em especial por seu The Coal Question (1865) - antes de ter publicado o seu livro A Teoria da Economia Política em 1871. E esses trabalhos tiveram, segundo Collison Black, uma aceitação melhor do que a sua proposta de economia teórica pura, devido "[...] ao simples fato de que eram estudos indutivos" (1962, p. 217), já que esse tipo de investigação estava bastante em voga na época.

(26) Ainda a esse respeito Jevons afirma: "Eu concordo com esses economistas eminentes [Leslie e Ingram] a ponto de aceitar que a investigação histórica é de grande importância" (Jevons, [1879] 1888, p. 20). E frisa que seria interessante que os economistas fizessem na sua disciplina o que Maine fez na Jurisprudência, ou seja: "[...] mostrar que todo [...] fato social é o produto do passado [...]" (Jevons, 1876, p. 622-623). 
O desafio historicista à economia política: uma análise do debate metodológico na Inglaterra na década de 1870

Eu não consigo facilmente conceber um assunto para investigação mais interessante ou útil do que aquele que o professor Leslie advoga e pratica. É absolutamente essencial que nós encararemos o presente à luz do passado; no entanto, eu discordo dele inteiramente quando ele defende que a economia política histórica deve destruir e substituir a teoria abstrata [...] (Jevons, 1876, p. 623) 27.

Ele acusa Leslie e Ingram de cometerem a 'falácia da exclusividade', e defende empreender, lado a lado, os dois tipos de investigação (teórica e histórica):

[...] ao invés de converter a ciência atual em uma ciência histórica, destruindo-a totalmente no processo, eu iria aperfeiçoar e desenvolver o que já possuímos, e, simultaneamente, erguer um novo ramo da ciência social sobre uma fundação histórica [...] A ciência da Evolução das Relações Sociais (Jevons, [1879] (1888), p. 20) ${ }^{28}$.

A resposta de Jevons ao desafio historicista foi, então, a proposta de divisão da Economia em vários ramos de investigação. Ele afirma que a Economia não deveria mais ser tratada mais como uma única ciência (Jevons, 1876, p. 624), muito pelo contrário:

[...] A subdivisão é o remédio. Temos que distinguir o elemento empírico da teoria abstrata, da teoria aplicada e da arte mais detalhada das financias e administração. Desta forma, irão surgir as várias ciências, tais como a estatística comercial, a teoria matemática da economia, a economia descritiva e sistemática, a sociologia econômica e a ciência fiscal (Jevons, 1879, p. xvi).

No que concerne ao campo da teoria econômica propriamente dita, no entanto, ele afirma enfaticamente que o método de investigação adequado seria o dedutivo e matemático. ${ }^{29}$ Para Jevons, os princípios básicos da Economia Política, por serem "[...] tão largamente aplicáveis que podem ser considerados universalmente verdadeiros no que concerne à natureza humana" (Jevons, 1876, p. 624), forneceriam uma base segura para a teoria dedutiva, abstrata e matemática da Economia Política ${ }^{30}$. E seria essa teoria (abstrata, dedutiva e universal) que forneceria a chave para a interpretação dos eventos históricos. Para Jevons, “[...] [d]a mesma forma que há uma ciência geral da mecânica, há uma ciência geral ou uma teoria da economia" (Jevons, 1876, p. 625). São as leis da ciência geral (da mecânica ou, no caso, da teoria

(27) Ele acusa Leslie de querer eliminar o método dedutivo na sua crítica à economia ortodoxa: "[...] no que se refere ao destino do método dedutivo, eu discordo totalmente [... ] do Sr. Leslie; ele é a favor de seu abandono [deletion]; eu sou por uma ampla reforma e reconstrução" (Jevons, 1879, p. xv).

(28) Sobre os historicistas ele afirma que "[...] podem ter sucesso na construção da nova ciência, mas eles não vão revolucionar e destruir totalmente a velha da forma como parecem supor" (Jevons, 1876, p. 624).

(29) Na Introdução à Teoria da Economia Política ele reproduz (de forma surpreendentemente elogiosa) a defesa metodológica que Mill faz da dedução na Economia a partir de algumas leis psicológicas simples conhecidas por introspecção (exemplo, que um ganho maior é preferido a um menor). A única diferença considerável entre a metodologia da ortodoxia vigente e a de Jevons dizia respeito à sua visão de que a Economia, além de ser dedutiva e abstrata seria também matemática na sua natureza.

(30) A esse respeito Jevons afirma: "A teoria da ciência [the theory of the science] consiste daquelas leis que são tão simples na sua natureza, e tão profundamente fundadas na constituição do homem e do mundo externo, que permanecerão as mesmas ao longo de todas as épocas sob nossa consideração" (Jevons, 1876, p. 625). 
econômica) que estarão subjacentes e, portanto, que irão ajudar a explicar as ocorrências específicas ${ }^{31}$ :

[...] A economia política histórica, longe de deslocar a teoria econômica, irá tão somente exibir e verificar a ação longa e contínua das suas leis nos mais diferentes estados (Jevons, 1876, p. 624).

Assim, apesar de genuinamente valorizar a história, fica claro que Jevons inverte totalmente o método proposto pelos historicistas. Ao invés de chegar aos 'princípios econômicos' por meio de um estudo indutivo e histórico minucioso, ele propõe entender a história à luz dos princípios universais e imutáveis da teoria econômica.

Jevons, de fato, abre um espaço para a indução e para a investigação histórica, mas certamente não aquele almejado pelos historicistas. Ele aceita esses métodos nos ramos aplicados e históricos da Economia, mas não só os exclui do domínio da teoria econômica, como não deixa dúvidas quanto à primazia da teoria dedutiva e universal em relação aos demais campos de investigação econômica.

Desta forma, ele claramente rejeita tanto o relativismo teórico de Bagehot (que restringia a validade da ciência dedutiva da Economia Política aos estados avançados como a Inglaterra), como o dos historicistas (que reivindicavam que cada sociedade seria regida por princípios diferentes, que deveriam ser descobertos de forma histórica e indutiva).

Fica claro então que, embora Jevons tenha mantido relações cordiais com os historicistas, eles se encontravam em campos opostos na disputa metodológica. ${ }^{32} \mathrm{E}$ as diferenças existentes não escaparam aos historicistas. Cliffe Leslie descreve nos seguintes termos a solução jevoniana:

O Sr. Jevons concorda totalmente com a necessidade da indução histórica para estabelecer os fenômenos econômicos da sociedade e suas leis, mas a colocaria aparte como um ramo da ciência da sociedade sob o nome de sociologia econômica, restringindo o termo

(31) Ele dá um exemplo dos esquimós, que têm hábitos concernentes à propriedade diferentes, mas que podem ser explicados com base nas leis universais da teoria econômica. Observa-se que se um esquimó tem dois barcos e outro não tem nenhum, o primeiro deixará com que o segundo utilize o barco (e eles não têm o hábito de devolver o que pegam emprestado). Jevons explica esse fato recorrendo à lei da utilidade marginal decrescente, o primeiro barco é fundamental para sobrevivência, mas a relevância do $2^{\circ}$ é bem menor e, por isso, pode ser dispensado. Assim, ele explica as diferenças culturais com base nos mesmos princípios utilizados em outras sociedades (Jevons, 1876, p. 623). Jevons chega a sugerir que os princípios da Economia são tão universais que valem mesmo para animais mais evoluídos como cachorros: "Eu não devo desistir [I should not despair of] de traçar a ação dos postulados da economia entre algumas das classes mais inteligentes de animais. Os cachorros certamente têm ideias fortes, apesar de talvez limitadas, de propriedade, como você rapidamente descobre quanto se coloca entre o cachorro e seu osso" (Jevons, 1876, p. 624).

(32) Essa também é a posição defendida por Collison Black: “[...] parece correto interpretar que Jevons foi atacado, e não apoiado, pelos escritos da "escola histórica inglesa"' (Collison Black, 1962, p. 214-215). Apesar disso, o mesmo comentador afirma que ao final da década de 1870, quando já começava a ter sua teoria reconhecida, Jevons pôde se dar ao luxo de '[...] adotar uma visão magnânima de tais críticas e tratar a visão histórica da Economia como complementar, e não simplesmente rival, à visão matemática [...]" (Collison Black, 1962, p. 215). 
O desafio historicista à economia política: uma análise do debate metodológico na Inglaterra na década de 1870

economia política [...] à teoria deduzida a partir de fatos conhecidos, axiomas ou hipóteses sobre a conduta ditada pelo interesse pessoal (Leslie, 1879, p. 158).

E em seguida rejeita explicitamente essa proposta de separar a investigação histórica da teórica ao afirmar: "[...] tudo o que Sr. Jevons classifica aparte sob o nome de sociologia econômica, tem o direito lógico a um lugar dentro do domínio da economia política" (Leslie, [1879], 1984, p. 158).

Para os historicistas, a teoria econômica de Jevons estaria sujeita à maior parte das críticas dirigidas à Economia ortodoxa. Ela também partia de um 'homem econômico' - que maximizava utilidade ao invés de riqueza - era dedutiva, abstrata e desconsiderava as diferenças culturais e históricas existentes entre diferentes povos e épocas ${ }^{33}$. Além de tudo isso, eles também consideravam uma perda de tempo o projeto, que era central para Jevons, de construir uma economia matemática ${ }^{34}$.

Todavia, no final das contas, como argumenta Peart, a solução 'conciliatória' de Jevons contribuiu para afastar a Economia do rumo almejado pelos dois historicistas irlandeses:

[...] ao final da década de 1870, com Jevons a empurrando, a economia se distanciou um passo de Mill e talvez dois dos Historicistas. Subdivisões, com a teoria econômica sendo colocada numa posição superior [...] inverteram a ordem científica imaginada por J. K. Ingram e Cliffe Leslie (Peart, 2001, p. 371).

\section{Considerações finais}

A 'batalha dos métodos inglesa' não foi resolvida na década de 1870 . Vimos que os historicistas não julgaram as respostas de Bagehot e de Jevons satisfatórias e os embates metodológicos continuaram, com outros protagonistas, ao longo da década seguinte, sem que nenhuma posição fosse capaz de unir a dividida comunidade dos economistas. A 'paz' só foi reencontrada com a publicação dos Princípios de Marshall no início da década de 1890 e com o consenso que conseguiu entre os economistas. ${ }^{35}$

(33) É fato que Leslie via como positiva a centralidade que Jevons dava à teoria do consumo. Todavia, havia divergências importantes entre eles sobre o método adequado à sua investigação. A sobre esse projeto de Jevons, Leslie afirma: "Um objetivo da economia política é certamente a substituição das abstrações vagas, tais como desejo de riqueza e aversão ao trabalho, por uma verdadeira teoria do que Jevons denomina de 'leis das necessidades/desejos' humanos. No entanto, uma ampla investigação histórica deve preceder a construção dessa teoria verdadeira [...]” (Leslie, [1879], 1984, p. 162).

(34) Sobre a matemática, que é, como vimos, uma inovação metodológica que Jevons introduz em relação à ortodoxia, Leslie também não se mostra entusiasmado. Para ele, esse método não seria adequado e nem expediente e afirma: "Lamentamos que tanto do raciocínio do Sr. Jevons é colocado em uma forma matemática” (Leslie, [1879], 1984, p. 160). Ingram, por sua vez, afirmou que o uso da matemática na Economia seria “[...] puro desperdício de poder intelectual sem qualquer futuro" (Ingram, apud Zouboulakis, 1999, p. 98).

(35) O livro Scope and Method of Political Economy (1890) de J. N. Keynes também colaborou para dirimir as discórdias dentro da profissão. De toda forma, como ressalta Coats: "Os anos de 1890-91 podem ser vistos como[...] encerrando uma fase de continuada controvérsia metodológica [...] Enquanto que os debates metodológicos continuaram na Alemanha e na Áustria, esse não foi o caso dos países anglo-saxões" (Coats, 1954, p. 151). 
Marshall acompanhou o debate metodológico e é seguro dizer que existe mais do que uma pitada de historicismo na sua obra. ${ }^{36}$ Ele abandonou a abstração homem econômico, e afirmou que a Economia "[...] lida com o homem tal como ele é [...] com o homem de carne e osso" (Marshall, [1920], 1982, p. 22), que tem diversas motivações, e nem todas autointeressadas (idem) - transcendendo, assim, a divisão entre 'verdades abstratas' e 'concretas' de J. S. Mill. Ele criticou duramente as pretensões universalistas da 'velha geração' dos economistas e enfatizou que a doutrina econômica não seria "[...] um corpo de verdades concretas, e sim um mecanismo de descoberta de verdades concretas [...]" (Marshall, 1885, p. 159), e que estas verdades poderiam variar (e provavelmente variariam) conforme as circunstâncias.

No que concerne ao método de investigação, ele se situou em um terreno intermediário entre os historicistas e Jevons. Se, por um lado, não aceitou a proposta historicista de uma economia puramente indutiva e ressaltou a importância da teoria na análise dos fatos ${ }^{37}$. Por outro, rejeitou veementemente a saída de Jevons de subdividir a Economia e desenvolver separadamente a teoria matemática, abstrata e dedutiva, de um lado, e o ramo indutivo e histórico da sociologia econômica de outro. Isso, na prática, teria o efeito de isolar o que Jevons chamava de 'Economia propriamente dita' (ou economics proper) dos fatos e da história.

Em carta a Edgeworth, Marshall deixa claro que considerava que aceitar a proposta de Jevons ou a dos historicistas seria como 'trocar seis por meia dúzia'. Para ele, ambas seriam igualmente parciais:

Na minha visão 'teoria é essencial. Ninguém consegue entender os problemas econômicos a não ser que trabalhe com ela. Mas eu não concebo uma noção mais calamitosa do que aquela de que a economia 'teórica', abstrata ou geral é a economia propriamente dita [economics proper] [...] o principal ponto do meu apelo é que o trabalho do economista é 'desembaraçar os efeitos conjuntos de causas complexas'; e que para isso, o raciocínio mais geral é essencial, mas um cuidadoso e amplo estudo dos fatos é igualmente fundamental; e que a combinação dos dois lados desse trabalho é o que caracteriza a economia propriamente dita. A 'teoria econômica' é, em minha opinião, uma impostora tão danosa quando se autoproclama ser a economia propriamente dita, quanto a mera história bruta não analisada [crude unanalyzed history] (Marshall apud Bladen, 1942, p. 23).

(36) Marshall não só acompanhou as discussões na Inglaterra, com também teve contato com as ideias dos historicistas alemães. Hodgson chega a afirmar de forma provocativa: "Marshall foi ele mesmo um produto e uma parte da tradição da escola histórica" (Hodgson, 2005, p. 342).

(37) Postura evidenciada na seguinte passagem: "Por mais ávido por fatos que o economista tenha que ser, ele não pode contentar-se com meros fatos [...] Ele tem que manter-se firme no projeto mais árduo de interrogar os fatos de forma a aprender o modo de ação das causas individualmente e conjuntamente, aplicando esse conhecimento para construir um corpo [organon] de teoria econômica, e depois fazer uso da ajuda fornecida por esse corpo [organon] para lidar com o lado econômico dos fenômenos sociais. Ele irá, assim, trabalhar à luz dos fatos, mas a luz não será dirigida diretamente, ela será refletida e contrastada pela ciência" (Marshall, 1885, p. 171). 
Desta forma, na opinião de Marshall, a Economia propriamente dita necessariamente envolvia uma combinação dos métodos dedutivo e indutivo. Como aponta Shove:

[A] resposta de Marshall [ao desafio lançado pela Escola Histórica] foi a por meio da combinação de métodos - não somente a história permeada por teoria, mas teoria (como nos Princípios) nutrida, modificada e ilustrada por fatos históricos e contemporâneos (Shove, 1942, p. 308-309).

Segundo Coats, "[essa] mistura de indução e dedução, análise matemática e nãomatemática, economia teórica e aplicada, desarmou os críticos [...]" (Coats, 1993, p. 107). É verdade que nem todos ficaram satisfeitos, mas um novo clima passou a prevalecer na comunidade de economistas e as controvérsias paulatinamente perderam importância.

No entanto, o rumo que a Economia seguiu no século XX, não foi exatamente aquele defendido por Marshall e sim algo bem mais parecido com a proposta de reservar espaços diferentes para o desenvolvimento da teoria econômica (abstrata, dedutiva e matemática) e para a história econômica. ${ }^{38}$ Como afirma Schabas: "[...] Parece que Jevons, ao estimular tanto o método histórico como o matemático, gerou o programa mais viável (Schabas, 1990, p. 112$113)^{39}$.

Talvez o próprio Marshall tenha, em alguma medida, colaborado para isso com a sua atuação institucional em Cambridge. Ele utilizou a sua enorme influência para criar um curso independente de Economia - disciplina que antes integrava o Tripos de Filosofia Moral. E a ênfase nesse novo curso recaiu sobre a teoria econômica, e a história e teoria aplicada ficaram em segundo plano - o que ajudou a mudar a formação do economista. ${ }^{40}$ Além disso, a sua decisão de preterir Herbert Somerton Foxwell, um economista com simpatias historicistas, e trabalhar pela candidatura de Artur Cecil Pigou para a sua sucessão na cadeira de Economia de Cambridge, significou uma guinada em Cambridge. Segundo Hodgson, a contratação de Pigou foi um marco, pois distanciou Cambridge das suas relações como historicismo (Hogdson, 2001, p. 110).

De toda forma, na década de 1920, o projeto historicista de transformar radicalmente o estudo da economia havia fracassado. A Economia já se encontrava compartimentalizada nas universidades entre teoria econômica, economia aplicada, e a história econômica. E foi nesse último campo que economistas historicistas acabaram por encontrar abrigo. Na descrição de Hodgson:

(38) Como aponta Schabas, apesar de garantirem a existência da história econômica dentro do currículo universitário, com sua luta os historicistas no fringir dos ovos "[...] não impediram o estudo da economia pura, e muito menos o uso da matemática. Nem resistiram à guinada em direção ao tratamento da economia de escopo universal [...]” (Schabas, 1990, p. 112113).

(39) Peart (2001, p. 371) afirma que "[...] seria simplista sugerir que Jevons sozinho foi responsável pelo estreitamento do canon econômico no final do século [...]", no entanto, também afirma que seria "temerário negligenciar [...] a influência do Jevons nesse debate e concluir que Keynes e Marshall sozinhos causaram a morte do historicismo na Inglaterrra" (idem).

(40) Segundo Hodgson, “[....] dois anos inteiros eram dedicados à teoria econômica, com apenas um ano sobrando para economia aplicada, história econômica e política" (Hodgson, 2001, p. 107). Para maiores detalhes sobre a formação do Tripos de Economia em Cambridge por Marshall ver Groenewegen (1988). 
Sendo gradualmente colocados de lado nas disputas acadêmicas, vários membros da Escola Histórica Britânica se direcionaram para disciplina de história econômica, abraçaram o empirismo e abandonaram a teoria econômica aos teóricos (Hodgson, 2001, p. 111$)^{41}$.

No entanto, apesar de não terem conseguido atingir os seus objetivos no que concerne à substituição da economia dedutiva, os historicistas conseguiram em alguma medida modificar a forma como a Economia era feita e apresentada. Como aponta Coats (1954, p. 152), por conta das críticas feitas pelos historicistas, as hipóteses adotadas passaram a ser explicitadas e qualificadas, os economistas começaram a ter mais cuidado ao se referir à teoria abstrata para advogar políticas e passou-se a ter um reconhecimento mais amplo da relação complementar entre dedução e indução do que existia antes. No entanto, segundo o comentador, com esses ajustamento e correções, os economistas “[...] preservaram a tradição ao cortar o solo por debaixo dos pés de seus críticos" (Coats, 1954, p. 153).

Houve, de fato, uma espécie de 'trégua' nos debates metodológicos. No entanto, como sugere Bladen (1941, p. 25), fica-se com a impressão de que elementos fundamentais do historicismo foram ignorados nos 'termos de paz'. A avaliação de Collini et al. em relação ao legado dos historicistas vai no mesmo sentido:

De fato, dentro da economia em si eles dificilmente ganharam qualquer vitória duradoura: [...] o rumo tomado no século vinte pela disciplina recentemente profissionalizada dificilmente era aquela demandada por Cliffe Leslie na década de 1870 (Collini et al., 1983, p. 274) ${ }^{42}$.

\section{Referências bibliográficas}

BAGEHOT, W. [1879]. Economic studies. In: BARRINGTON, Russel (Ed.). The works a life of Walter Bagehot, v.VII. London: Logmans, Green and Co., 1915.

(41) Em 1927, Ashley importante economista historicista do final do século, declara como $1^{\circ}$ presidente da Sociedade de História Econômica da Inglaterra: “[...] os economistas teóricos estão prontos para nos manter quietos ao nos dar um pequeno pedaço de jardim que seja nosso; e nós humildes historiadores ficamos tão gratos por um pouco de território livre de disputa que estamos inclinados a deixar os economistas aos seus próprios métodos" (Ashley apud Koot, 1980, p. 174-175). Koot diz que esse comentário de Ashley reflete uma insatisfação da sua parte com o papel que a história desempenhava na época: “Ashley [...]não estava disposto a aceitar a compartimentalização dos estudos econômicos em teoria econômica, economia aplicada e história econômica. Foi ao longo da carreira de Ashley que esses campos começaram a ser reconhecidos como disciplinas separadas, apesar de relacionadas, nas universidades britânicas" (Koot, 1980, p. 175). A sua pretensão era mudar a forma como a Economia era feita, mas não teve sucesso nisso, apesar de ter sido bem sucedido em consolidar a história econômica como uma disciplina independente (idem, p. 192).

(42) Todavia, Maloney afirma que esse fenômeno ocorreu somente dentro da Economia. Nas demais ciências sociais o historicismo continuou a ter influência: "A vitória quase completa da concepção dedutiva de ciência depois de 1890 é capaz de obscurecer o fato de que essa foi decididamente uma trajetória excepcional [deviant shift] dentro do contexto intelectual mais geral. O relativismo histórico continuou a dominar a sociologia, o direito, a antropologia, e mesmo, - graças ao trabalho de Herbert Spencer - a filosofia moral (Maloney, 1976, p. 448). 
O desafio historicista à economia política: uma análise do debate metodológico na Inglaterra na década de 1870

BLADEN, V. W. Mill to Marshall: the conversion of the economists. The Journal of Economic History, Supplement: The Tasks of Economic History, v.1, p. 17-29, 1941.

COATS, A. W. The historicist reaction in English political economy 1870-90. Economica, v. 21, n. 82, p. 143-153, 1954.

COATS, A. W. Sociological aspects of British Economic Thought (ca.1880-1930). In: THE SOCIOLOGY and professionalization of economics: British and American economic essays. London: Routledge, 1993. v. 2.

COLLINI, S. et al. Particular polities: political economy and the historical method. In: THAT NOBLE science of politics: a study in nineteenth-century intellectual history. Cambridge: Cambridge University Press, 1983.

COLLISON BLACK, R. D. The classical economists and the Irish problem. Oxford Economic Papers, New Series, v. 5, n. 1, 1953.

COLLISON BLACK, R. D. W. S. Jevons and the economists of his time. The Manchester School, v. 30, issue 3, 1962.

COLLISON BLACK, R. D. The political economy of Thomas Edward Cliffe Leslie (18261882): a re-assessment. European Journal of Economic Thought, v. 9, n. 1, 2002.

DEAN, P. The state and the economic system: an introduction to the history of political economy. Oxford and New York: Oxford University Press, 1989.

FOXWELL, H. S. The economic movement in England. The Quarterly Journal of Economics, v. 2, n. 1, p. 84-103, 1887.

GRAY, P. The Irish famine. London: Thames and Hudson Ltd, 1995. (Series New Horizons).

GROENEWEGEN, P. D. Alfred Marshall and the establishment of the Cambridge Economic Tripos. History of Political Economy, v. 29, n. 4, 1988.

HODGSON, G. How economics forgot history: the problem of historical specificity in social science. London and New York: Routledge, 2001.

HUTCHINSON, T. W. A review of economic doctrines 1870-1929. Oxford: Oxford Clareton Press, 1953.

INGRAM, I. The present position and prospects of political economy. The introductory address delivered in the Section of Economics and Statistics of the British Association for the Advancement of Science, at Dublin, 1878.

JEVONS, W. S. The future of political economy. The Fortnightly Review (New Series), v. $20,1876$.

JEVONS, W. S. [1879]. Prefaces and Introduction. In: THE THEORY of Political Economy. 3. ed. London and New York: McMillan and Co, 1888. 
Laura Valladão de Mattos

KEYNES, J. N. [1890]. The scope and method of political economy. In HAUSMAN, Daniel (Org.). The philosophy of economics: an anthology. Cambridge University Press, 1985.

KINZER, B. L. England's disgrace: J.S. Mill and the Irish question. Toronto: University of Toronto Press, 2001.

KOOT, G.M. T. E. Cliffe Leslie, Irish social reform, and the origins of the English historical school of economics. History of Political Economy, v. 7, n. 3, 1975.

KOOT, G. M. English historical economics and the emergence of economic history in England. History of Political Economy, v. 12, n. 2, 1980.

LESLIE, T. E. C. [1870]. The political economy of Adam Smith. In: ESSAYS in political economy. 2. ed. London: Longmans, Green \& Co, 1888.

LESLIE, T. E. C. [1876]. On the philosophical method of political economy. In: ESSAYS in political economy. 2. ed. London: Longmans, Green \& Co, 1888.

LESLIE, T. E. C. [1879]. Political economy and sociology. In: ESSAYS in political economy. 2. ed. London: Longmans, Green \& Co, 1888.

LESLIE, T. E. C. [1879]. Untitled review of the second edition [of Jevons's The theory of political economy]. In: COLLISON BLACK, R. D. (Ed.). Papers and correspondence of William Stanley Jevons. London: The Macmillan Press, 1984. v. 7.

MALONEY, J. Marshall, Cunningham and the emerging economics profession. The Economic History Review, v. 29, 1976.

MALONEY, J. Historical economics, British. In: DEULAUF, S. N.; BLUME, L. E. (Ed.). The New Palgrave Dictionary of Economics. 2. ed. 2008.

MARSHALL, A. [1885]. The present position of Economics. In: PIGOU, A. G.; KELLEY, A. M. (Ed). Memorials of Alfred Marshall. New York, 1966.

MARSHALL, A. [1887]. The old generation of economists and the new. In: PIGOU, A. G.; KELLEY, A. M. (Ed). Memorials of Alfred Marshall. New York, 1966.

MATTOS, L. V. Transformando 'verdades abstratas' em 'verdades concretas': uma análise sobre a metodologia econômica de J. S. Mill. Estudos Econômicos, v. 34, n. 1, 2004.

MILL, J. S. [1844]. On the definition of political economy and the method of philosophical investigation in that science. In: CW IV. Toronto: University of Toronto Press, 1967.

MOORE, G. T. E. Cliffe Leslie and the English Methodenstreit. Journal of the History of Economic Thought, v. 17, issue 1, 1995.

MOORE, G. Bagehot as an applied economist. Journal of the History of Economic Thought, v. 18 , issue $2,1996$. 
O desafio historicista à economia política: uma análise do debate metodológico na Inglaterra na década de 1870

PEART, S. Theory, application and the canon: the case of Mill and Jevons. In: FORGET, Evelyn L.; PEART, Sandra (Ed.). Reflections on the classical canon in economics: essays in honor of Samuel Hollander. London: Routledge, 2001.

PERSKY, J. Retrospectives: the ethology of homo economicus. Journal of Economic Perspectives, v. 9, n. 2, 1995.

ROBERTSON, R. M. Jevons and his precursors. Econometrica, v. 19, n. 3, 1951. Available at: http:www. jstor.org/stable/1906812. Accessed: Jun. 10, 2016, 19:26:47.

SCHABAS, M. A world ruled by number: William Stanley Jevons and the rise of mathematical economics. Princeton, New Jersey: Princeton University Press, 1990.

SHOVE, G. F. The place of Marshall's principles in the development of economic theory. The Economic Journal, v. 52, n. 208, p. 294-329, 1942.

TRIBE, K. Historical schools of economics: German and English. (Keele Economic Research Paper (KERP 2002/2). Download: www.keele.ac.uk/depts/ec/web/wpapers/kerp0202.pdf.

ZOUBOULAKIS, M. Walter Bagehot on economic methodology: evolutionism and realisticness. Journal of Economic Methodology, v. 6, n. 1, 1999.

ZOUBOULAKIS, M. Contesting the autonomy of political economy: the early positivist criticism of economic knowledge. European Journal of Economic Thought, v. 15, n. 1, 2008. 